\title{
Application of the ITIL Method for Management in Practice
}

\author{
Domagoj Car ${ }^{1}$, Miroslav $\mathrm{Car}^{2 *}$, Mirela $\mathrm{Car}^{3}$ \\ ${ }^{1}$ Phoenix, Zagreb \\ Republic of Croatia \\ ${ }^{2}$ Faculty of Mechanical Engineering and Naval Architecture, University of Zagreb \\ Zagreb, Republic of Croatia \\ ${ }^{4}$ Faculty of Mechanical Engineering and Naval Architecture, University of Zagreb \\ Zagreb, Republic of Croatia \\ *Corresponding author's email: car.miroslav [AT] gmail.com
}

\begin{abstract}
The chosen basic and the most important one is the ITIL method. An investigation hypothesis is set, that system and processes are not in sufficient measures in line with theoretical settings from the literature and with some of those are from good practices. It is researched and conducted in the spirit of analytics with the aim of alternative and possible better application of ITIL legality. Collected and analyzed facts and data are compared with the theoretical settings of the ITIL method in management with my own 10 years of experience, knowledge and skills, applicable in good practices. By applying previously cited entries, there is a need to propose ways and conditions of correction of applying the ITIL method, with more successful results. Entire procedures of the ITIL Method are supported by IT. Acknowledgement is dedicated to Domagoj Car, bacc.oec., because of processing his own Expert final work on Graduate studies.
\end{abstract}

Keywords--- management, manager, ITIL method, IT support

\section{INTRODUCTION}

The structure of introduction for Expert final work include the following usual elements: problem of investigation, investigation, subject of investigation, object of investigation, postulate of investigation, beside the belonging explanation. The problem of investigating thoroughly is explanation in ABSTRACT (basic method of management, comparison of collection data with theoretic postulates of ITIL method for management and with his own 10 years of experience, knowledge and skills of the first co-author Domagoj Car, and by establishing the possible causes and mechanisms for such deviant work, application postulates of theory and good practice for ITIL method and management, as well as proposition of methods and conditions for correct work of ITIL methods and management. Subject of investigation: basic or main element of the subject of investigation is ITIL methods, with its various types, conditions, documents, decisions and etc. Object of investigation: object is corporation, with all existing elements of this. One of the basic parts is Service Management Department (SMD ), and one of its part is Service Desk (SDk), in which the first co-author Domagoj Car has worked more than 10 years. Postulate of investigation: previously cited system and processes are not coordinated in sufficient measure with one of part of theoretical postulate from references and from good practices. Because of the seriously questionable and inaccurate procedures in the application of the ITIL method with it, there is a need to conduct investigation, and from its results to conclude on ( non ) existing significant differences between theorethic postulates and real work, and point out a possible problem solving. Entire ITIL methods are supported with IT. Acknowledgement is dedicated to Domagoj Car, bacc.oec., because of the processing of his own Expert final work on Graduate studies. 
The concept and content of management and managers, [ 3, pp.1 to 9, p. 9 to 24, p. 87 to 97 ]. From a number of points of view, the management concept has been chosen to determine the concept and content of management, and the organizational view of management has been chosen most often. Two basic groups of functions are common in an organization: a control group of functions for organizing, coordinating and directing an operational function (management, leading and executing, and managing), and an operational group of functions for performing the task of the organization and performing the work (production, finance, commercial, personnel, etc.). In terms of the connection between the terms management, organization and administration, the most acceptable, given the precision and uniformity of the content, is the division that considers the term administration as part of the term management. In the desire to define the term Management, it is easy and quick to determine that the same is a very complex term, and to define which two distinct types of problems arise: the one semantic in nature (the term organization is not ambiguous, there are four basic categories of term organization: universal, institutional, structural and functional; everyone and their characteristics; Hoffman, F. in Begriff der organization, pp. 1425-1432, 1980, and the substantive nature. the latter, the appearance of intertwining and overlapping concepts of management and organization suggests that management it cannot / must not exist outside the organization, regardless of its categorization / affiliation and definition, so it is reasonable to conclude about the inseparable genesis of organization theory and management theory. In 1903, F.W. Taylor published Shop Management, and thus were born the concept and scope Scientific management (Scientific Management SM). The content nature of the term, also points to the problem of ambiguity of the term, which refers to more subterms. Used different definitions of management, and the theory and literature show that the majority of authors accept subterm process as the basis for the definition, since it allows and justifies the chosen term and name of the process, with activities related to the management function, for example: Koontz, H., Weichrich, H., in [10] Management, p. 4, from 1990, Hellriegel, D., Slocum, J. W., in [19] Management, p. 6-7, from 1998. and Kreitner, R. in [11] Foundations of Management ..., p. 4, from 2006. define the management of the same or close concepts (the work of individuals together with groups; with the help of others; with others and with the help of others). H. Fayol expressed his conception in the early twentieth century, while P. Drucker introduced his conception half a century later. Given the periods in which they occurred, it is quite understandable that there are several important differences between them, but also some of the same or very similar characteristics. Fayol's conception is rigid, where the terms are strictly edited (partly borrowed from military terminology). Drucker's concept is distinguished by the shift of focus from the command function to the functions of motivation, and the most distinguished by two new moments, namely: a different attitude towards people, much more insists on "forming staff", "communicating", "motivating" staff instead of "commanding" and "controlling", etc .; Drucker points out what is today called the "quantitative" view of management. It sets before the management tasks to formulate the goals in figures or, in general, in measurable sizes, to create instruments for measuring the achieved results and to measure and evaluate the results together with the executors. The authors cite a different number of areas in management, but still most of them consider that management consists of five functions. Thus Koontz, H. and Weichrich, H. in [10, p. 15 to 18 ] from 1990 list five basic functions for successful management, each with its own characteristics, which are: Planning- Organization- StaffingLeading- Controlling.

Defining the term and content manager. A manager is the person of the primary tasks, that emerge from the management process: that is, he plans and makes decisions, organizes work and business, engages and guides people, and controls human, financial, physical and information resources. There are several definitions, some of which are: the manager, given the considerable scope and complexity of the job, does not do the job alone with other people and with the help of other people (for example, his subordinates, staff specialists and others). In doing so, he must find ways to motivate participants in the process, with the purpose to increase its overall effectiveness and efficiency, taking into account its social responsibility. Management activities are performed not only by the listed participants through whom the tasks are performed, but also by non-managers (experts-specialists, for example, for the development of a plan, the preparation of organizational solutions, etc.). in [2] Boddy, D. and Paton, R.A.: Management: An Introduction (1998), p. 22. From an enterprise point of view, it is not enough for someone to be a manager, but it is important whether he or she is an effective manager, or whether he or she has any of these attributes: a manager as an active leader, positive work environment, the ability to achieve high performance, a thorough knowledge of the business and organization of the business in the broadest sense of the word; incentive to achieve high performance, identify motivational factors (job interest, leadership style, relationships with associates, company policy, salaries and more). Although these management functions are achieved by all managers in the company, the degree of their time burden is not the same. It was alleged that managers on account of different levels perform five of its basic functions, as well as to each of the five management functions is realized by executing a series of activities, that can be viewed from two perspectives: first, observe the activities of managers from the viewpoint of daily work, and the other observes the same action from the point of view of the role of the manager in the performance of his job: If one looks at the daily job of the manager, one will notice not 
only the numerous and varied activities he performs, but also all the feverish and dramatic nature of his work. His field of activity is so wide that he has little time to think calmly. From the point of view of the role that the manager has in performing his job, and from the standpoint of the organizational behavior of the manager's role, they can be differentiated and classified. Thus, for example, Mintzberg, H., in [12] of 1979, identified 10 specific managerial roles that can, again, be grouped into 3 different types, namely:

(1) interpersonal role: refers to the development and control of interpersonal relationships,

(2) information role: refers to the fact that the managerial function is a central place for collecting and distribution of information;

( 3) decision-making role: derives from the powers that the manager has in the decision-making process.

Managerial skills. The manager's job is complex and multidimensional, because many activities are contained in the functions performed by management. That is why, in order to perform this job successfully, he needs skills, which implies a set of special abilities that result from knowledge, information and talent. Although some management researchers suggest broad lists of these skills, they can still be summarized into four categories, each with its own characteristics. They are: conceptual skills, human skills, technical skills, design skills.

The representation of these skills by management level is different, but managers must have each of them to the extent necessary to successfully perform their functions. The interdependence of the representation of individual skills by management levels can be represented graphically, while the described interdependence of the same would show the following: conceptual and design skills are most important for top management. Technical skills are most important for executives (non-managers) and the first level of management (managers, supervisors, various heads of departments, etc.) Skills of working with people are of great importance for all levels of management, and are not negligible for non-managers, because they work with people, with their co-workers or with direct managers.

\section{Management Systems and Processes, [ 3, p. 7, p. 16 to 23, pp.24 to 27, p. 98 to 117, p. 143 to 170 ]}

Each larger organization applies in practice one or more types of organizational structures, which necessarily contain a system of leadership and management, and which understands the various forms of leadership and management. The structure of the management system contains: determination of the system; basic categories to be incorporated into the system; principles, styles and methods; holder of managerial function - subject. Systems can also be viewed, most often, from the point of view of their organization and from the point of view of their functioning.

Management systems in terms of their functioning. Organizational theory and practice link the structures of organization and management, and then divide them in the first level into groups into classical (line, function, line-head or head-line) and modern or flexible (project, matrix, team, etc.), each with its own distinctive features.

Systems management from the viewpoint of their organization. The management system or models are defined according to use of their functioning. In practice, two tendencies emerged: standardizing the actions of managers and top managers, and defining systems or models of manager functioning. Three more complex systems are known, namely: a) POSTCORB: according to Vila, A. in [19] in 1994, by L. Gulick, in 1937 established a management model (the abbreviation of the model is the compound of the initials of the constituent words; b) McKinsey Model 7S: a slot by Tony Petters and Robert Waterman of McKinsey Co. 1982, with 7 variants in 7S; c) KSM corporate management system: more importance was given to characteristics such as: communication, creativity, interesting work, part-time and participation, all with the goal of increasing the efficiency and contributing to satisfying self-actualization motives, fulfilling their own potentials and achieving the optimum amount of independence. It was elaborated by the famous humanist philosopher Abraham H. Maslow in the classic psychological work "Motivation and Personality" in [ 13] , in which he also described a hierarchy of needs. KSM 's corporate management system focuses on the leadership function, although it also contains other management functions; an open system that can evolve and adapt to dynamic changes in the environment; a set of principles and rules that focus on common ground; it is aimed at motivating each other to accomplish different tasks: the goal is to achieve efficient work and people satisfaction through cooperative leadership. They are, according to Becker, H. and Longoch, I. in [1] 1999, mutually conditioned. KSM elements are factors with an expectation of achieving the goal of a leadership function, namely performance and satisfaction. Elements are observed, analyzed and evaluated individually, but an even more important is the interaction, integral and synergistic approach; there are positive and negative effects, but positive potential and effects must prevail; the basic goal is that in KSM cooperative elements prevail over the line / individual ones. The KSM Global Approach indicates that research in the 1990s showed that KSMs functions are multilayered and have their own structure that can be interpreted from multiple perspectives, so the management and leadership systems can be referred to as flexible categories with appropriate structure. 
Elements of Management Systems, [3, 18 through 20; 7, p. 1 through 13]. Management is a set of rules structured into an organizational management system, based on the necessary elements for functioning and implementation in practice, which are the basic categories. They are: authority, responsibility, delegation of authority and responsibility, and hierarchy. The minimum information on each of them is mentioned below. To a degree, each category is independent, but is then interdependent under the influence of factors such as: organizational concept, organizational structure, distribution of power, organization policy, and cultural, political, economic and other factors. Authority (Authority A): In defining the concept of organizational authority, there are different definitions of authority, such as law, legitimate law, power, etc., the right to order according to Grochla, E., in [ 8] from 1978, etc. Organizational authority refers solely to a job or function; there is an administrative proportion in the hierarchy, from the highest levels of jobs and functions to the lowest. Law is administratively proportional to responsibility. Authority classifications can be made because of the existence of multiple types of authority, based on the characteristics of the function holder. According to the organizational approach, in terms of alignment of organizational structure and managerial processes, there are three basic types: line, pivot and functional, each with specific characteristics. One common classification would be: original (natural) authority: based on ability (knowledge, skill, motivation) and morale; derived authority (function authority): based on a job position or function in the division of labor; status (positional, hierarchical, functional, formal, etc.) authority: acquired / achieved by occupying certain positions in the leadership structure; charismatic authority; expert authority (knowledge authority): acquired by professional knowledge and skills in the process of work and leadership; political authority: acquired through the support of political structures; traditional / conservative: use of traditional titles, titles, etc., such as owners, king, and lower-level emperors, most often acquired through inheritance, had to strive to combine more objective types, containing the qualities of analog managers, such as abilities (knowledge, skills and motivation), morals, etc., which in total constitute the authority of a manager recognized by superiors and subordinates, but also by the environment. Unique rules are: superiors directly control subordinates; responsibility for each level's decisions is accurately located; communication is easy; were established hierarchical relations called "chain of command, lines of command, scalar chain", etc. Responsibility (Responsibility $\mathbf{R}$ ): the accountability represents a fundamental and assumed category of systems management (standardized or the actual responsibility of the sanctions or taking measures, of the mildest to the most severe, for example: misdemeanor, criminal and others). Responsibility is the relation to organizational issues and socially acceptable norms in organizational relations (legal norms, political and ethical). Establishing accountability is always effectively possible only individually, if an individual is responsible to only one known leader. Administrative proportion applies: workplace or higher-level function-greater responsibility, and lower-level jobs and functions-less responsibility. Delegation of authority and responsibility (Delegating for Authority and Responsibility DAR): every more complex organization has built-in delegation of authority and responsibility as an important management skill right down to the low levels of the organizational structure, and that is decentralization. This means the transfer / delegation of tasks, authority, or decision-making and command rights, to lower levels of leadership and manager, who will be responsible for the execution of the above. Regardless of the type of organizational structure and type of organization, the axiom in delegation that every manager must know. One can delegate work all over the pyramid of the hierarchy, but one cannot fully delegate responsibility. Hierarchy (Hierarchy $\mathbf{H})$ : term hierarchy in the system of management is contained in the structure of official relations, according to their quality is determined in the category system leadership. Of the more definitions of the term hierarchy, one more common and familiar would be: Hierarchy is a set of legitimate relationships and real interpersonal relationships in the system and in the management process, and expresses the complete relationship between associates, departments and organizational units, as well as relationships between management and individual managers. In practice, the concept of hierarchy can be achieved in three ways: by subordination; coordination, the optimal combination of subordination and coordination.

The principles in the management (Principles and Management PIM). To the questions that the principles used in the management and leadership, a simple and accurate answer would be: to use the principles appropriate to the class and the type of organization and tasks, the level of the environment and other factors. The management system and function are based on certain principles, which all managers and leaders must consistently adhere to, but this fact has prompted many researchers to identify and find universal principles. At the same time, they found that when setting universal principles, there are two types of universal principles, namely: universal principles with two subtypes of common principles (universal general common principles and universal special common principles; integrated universal principles). The principles must ensure the effectiveness of management processes and the entire organization, and therefore refer to both leadership and management (superiors) and executors (subordinates).

Management Levels / Types, Roles and Profiles (Levels / Types of Management, Roles and Profiles of Manager L / TMRPM) In this approach, the basic criteria of the delineation of management levels and leadership are the types of decisions that are made by leaders, where three levels of management are identified / recognized that differ from each other by the type of tasks they perform and by the type of decisions: types of management in terms of hierarchical 
levels in managerial jobs and types of management in terms of scope of responsibility. Important determinants of managerial work is hierarchical level, and there is talk about the so-called vertical differentiation of managers. The first type is usually divided into three hierarchical levels of management: top managers (managers at the highest level). This top management ranks of managers at the highest hierarchical level and are responsible for the enterprise as a whole; middle management: made up of managers at the middle level of the organizational hierarchy, and are responsible for the business units and the main departments in the company. However, to ensure coordination between individual jobs, there is an increasing need for project managers or team managers. Project manager is only responsible for temporary work on a project that involves the participation of others at a similar level in the company; lower or first line (eg., lower or firstin) line management is made by managers directly responsible for the production of goods and services. For the second type, the main difference in managerial jobs is expressed in their area of responsibility. This is the so-called horizontal differentiation. For the third type, the application of general system theory in organizational theory, based on the application of general system theory in organizational theory, there is also the following classification of management levels: direct or operational level (leadership) leadership, intermediate or coordination level strategic, supreme, main or general level of management.

Organizational roles (hand) of leaders and managers. The difference between individual levels and jobs or functions is not so important from the point of view of the hierarchy in the organization, because the hierarchy can be structured on a staff or other, rather than on organizational criteria. That's why differences are really noticeable in organizational roles that are structured at individual levels of management. In order to reflect the consistency of the management system and organizational order, it is possible to analyze the characteristics of specific organizational roles at each level. From the standpoint of organizational behavior, the roles of managers can be distinguished and classified. Thus, for example, Mintzberg, H., in [14] of 1979, identified 10 specific managerial roles that can, again, be grouped into three different types, according to a well-known division : the interpersonal role; information role; the role of decision making. Summarizing individual managerial roles at different levels can lead to the aforementioned and known ones: chief (supreme, general) management or manager (strategic or top management); middle management: the characteristic is that they are a category of this level; direct leaders: this is a model in which the leader is in direct contact with the executor.

Knowledge and skills of successful managers. At all three levels are management activities that require specific knowledge and skills to successfully complete the job. Since becoming a scientific organization of work and management, researchers have sought to answer the fundamental question: What are the characteristics of a person / personality, what knowledge and skills does a person need to become a successful manager? Different levels of knowledge are required by management level. When it comes to skills, senior authors (mainly psychologists) point to social, strategic and conceptual skills. These types of skills also differ in jobs at different levels and are therefore needed in different variants, according to Sikavica, P., Bahtijarević-Šiber, F. in [17] of 2004. Recent approaches to the skills required for successful management state a "mixture or a mix of skills required for particular levels of management and mention four types of skills: conceptual, computer, technical and social skills, C. Devenport in [4] of 1989. At the top of the rankings, at $87 \%$, is honesty as a core virtue, followed by honesty, reliability and tolerance, which are all ethical categories and have the highest degree of preference. This is followed by ability, intelligence, etc., that is, professional qualities, and then personality traits (courage, reliability, etc.). In the commentary of the previous interrogation, Srića, V., at [ 18 , p. 145 ] of 1992 says: "In our cultural environment, entrepreneurship and management are not considered honesty-based jobs. On the contrary (...), foreign partners, accustomed to honesty, believe that the word is enough, many of our business people are not even bound by the signed contract. "

\section{APPLICATION OF ITIL METHODS WITH MANAGEMENT IN PRACTICE}

Opinions were presented, first of all, by the author of the Thesis Domagoj Car, in accordance with the accepted knowledge from a practical operational perspective, and then others, including the necessary theoretical assumptions. In today's current ITIL-based companies, more management perspectives need to be covered. Systematic use leads to the coverage of daily systematic work in the form of receiving, processing and follow-up on necessary open issues. The rhythm of the present day has opened up questions for modern, especially IT companies, that seek the proper processing of information given the scope of the information. ITIL (Information Technology Infrastructure Library) has introduced a methodology that greatly contributes to quality processing, but also within the organization itself and in the structure of modern organizations. The concept of ITIL is shown in Figure 1. and is summarized below. This half will be covered in the application of the company, which is based on the concept of ITIL, where the part of management related 
management applications, management of incidents (Incident Management IM), change management (Change Management CM ) and, consequently, for the management problem. Consideration should also be given to the service level management service (Service Level Management SLM), which provides a level of security for contracting parties regarding the level of service.

The idea behind putting this into practice is to compare existing in-house implementation and a possible alternative to streamline the process to cover unspecified channels. As an employee of a company whose primary objective is to provide, in accordance with SLM, contracted service levels for each of the solutions provided, it is necessary to set up a system, previously agreed, on the possibility of agreeing the service level of Service Level Agreement SLA, so that the same can be guaranteed, and which requires the implementation of a set of methods to evaluate the existing situation and processes that are applied in the selected company. The basis of quality service in the ITIL process is in the transitions through stages that have reached maturity, to be applicable and to be guaranteed. An overview of the service cycle is shown in Figure 2. An understanding of a new service is required through several basic stages. Following the accepted idea of designing a service (Service Design SDn), it is necessary to pass the Service Transition ST phase, in which the service intended to be offered to partners is refined with the proper technical design, in the form of technical solutions as well as solving potential performance problems.

The next step is the transfer to the service phase (Service Operation with Department SOD), where the application within the selected company starts and is given to the partners as a finished product, which enables the application and agreement on the levels of service to be covered by the Service Level Management SLM. The impact of the SOD phase on the ITIL business of the selected company is shown in Figure 3. The Service Request cycle is shown in Diagram 1. ITSM service life and connectivity is found in Diagram 2 .

On the issue of higher levels of work selected companies and services, it is necessary to incorporate the concept of crisis management (Crisis Management CM) as well as a disaster recovery services (Disaster Recovery DR), a solu tion of which I will later write more in correlation of working with the SOD runtime service phase. About the idea and implementation of the SOD phase will be written more in terms of application in practice, as well as in monitoring the life cycle of a service or product, which will be supported by practical work in an ITIL based company. The impact of the Service Desk SDk department within the SOD runtime service phase , as well as the management elements involved, on the day-to-day business of the modern ITIL based company is shown in Figure 3. The Service Desk SDk is the primary communications channel, whose primary task is to properly download, process and identify potential problems and threats to daily business. As the main channel for receiving applications and controlling inputs from partners or users, it is necessary, in accordance with ITIL, to include it in the practical part, but also in other forms of support, both for the company and for the interests of partners. The previously described Service Desk SDk is directly involved in the sphere of access service (Access Management AM), to monitor the level of entitlements granted to certain users and potentially prevent them from being wrongfully used or misused.

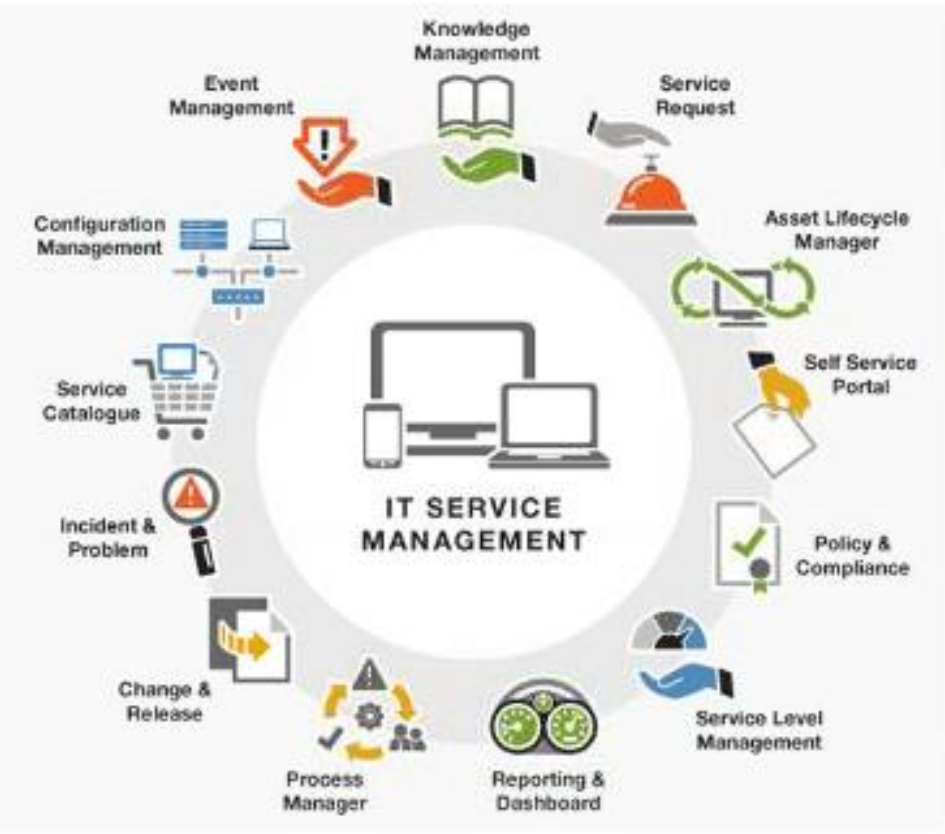

Figure 1 . Concept of ITIL Method

Source : https: /www.uk.insight.com./en.gh/shop/landedk/itsm-in-cg, situation on 01/10/2017. 
Although the primary task of Request Fulfillment RF services is to ensure that partner inputs are monitored for inputs of information. Following the previous practically includes in service incident management (Incident Management IM), which shows the transition of applications in the incident which should be correctly processed and focus, or to the execution and recovery services, or to detect a potential problem that will be further accompanied by recurrence of a problem management service (Problem Management PM). The practical application will show the example of the processing requirements to be recognized as an incident, and following the problem, which will further be accompanied in order to prevent recurrence, in this idea applied will base management service incidents and problems, and the PM and IM, as and the implications of the SLM level management service that will introduce the term Service Deterioration SDt, which directly illustrates the impact of a repeat incident that disrupts the level of service guaranteed to a partner. It will also include the notion of a Production Change PC service, which may be directly related to corrections or modifications to the service or to introduce new options in existing services, as well as the introduction of new services through a body called the Advisory Body for changes (Change Advisory Board CAB), whose main task is to minimize the consequences of the production implementation for partners and to ensure the proper perception of the impact on existing business for the purpose of satisfying the service level, which is part of the SLM. Modern organizations continuously increasing their dependence on IT in and its efficient support in the realization of business strategy This tendency supply and a growing need to ensure quality applications and IT services that are in line with business requirements.

Work and correlation of Service Desk in an IT company. The key to an effective Service Desk SDk is to ensure clear accountability and define roles for demonstrating Service Operations Department SOD phase practices. Roles within departments are determined by the size of the organization, the way it is structured, the existence of external partners and other factors.

Service Desk SDk, Roles and Accountability. The following roles are required for Service Desk SDk, with special note that job relationships should be clearly defined, which must be drafted and agreed so that responsibilities are known. The roles are:

(1) Service Desk Manager SDM. Significantly in large organizations, SDk manager may be justified with the role of a supervisor; (2) Service Desk Supervisor; (3) in small teams, it is possible for the Senior Desk Supervisor role to be the supervisor, but in larger teams, the separate role of Service Desk Supervisor and Senior Service Desk Analyst is probably required. In the situation of shift work, there are also a larger number of employees. The role of the supervisor / senior analyst (Service Desk Manager SDM) includes the following actions: maintaining the level of skills of staff during working hours distribution of responsibilities; activities undertaken by the Human Resources department; assuming the role of primary escalation contact for difficult jobs; creating statistics and management reports; introducing Service Desk SDk at meetings; organizing staff training; liaising with senior managers; linking to management change in $\mathbf{C M}$ production; informing Service Desk staff of changes or implementations that may affect the workload; assisting analysts as a first line of support for increasing business load,

(2) Service Desk Analyst SDkA. The primary role of the Service Desk Analyst is first level support for incoming calls and solving incidents or requests for services, using incident management and meeting requirements (Request Fulfillment RF). Additional roles include the following activities: (a) incident control: management life cycle of all service requirements; (b) communication: maintaining customer awareness while progressing and coordinating possible solutions. Features Service Desk SDK in or about the Call Center CC and Help Desk HD with previously stated bears a role, that serves as a coordination channel for activities such as requests for change (Change Request CR), maintenance of contracts, license software tools, SLM, service configuration (Configuration Management CM), maintenance services (Availability Management AM), Financial Management Services (Financial Management FM) and Continuous Management IT Services (Service Continuity Management SCM ).

Based on the definition and operational experience of the first author Domagoj Car, it can be concluded that the Service Desk SDk has no responsibility for all the processes / procedures it runs. For example, the Service Desk receives a service request request (Request Service RS), but the Request can be resolved by an internal operating team. In the company where the co-author Domagoj Car is employed, the co-author performs a hybrid function in the form of Service Desk Analyst / Service Desk Specialist, the same is a combination of a direct detection of the type of RF request itself , categorization in the form of events, incidents or problems and solving it in situations where due to complexity it is not possible to include information processing and forwarding for further analysis. In terms of purpose and location as time coverage, the SDk can be divided in a number of ways and it is necessary to look at the location division to cover various support for the IT service NON-STOP 24/7).

Divide of Service Desk SDk in IT firm by location. The Service Desk division (one form exists in an applied IT firm) is as follows: (1) the concept of a local Service Desk. A common concept of work, it helps with 
communication but is often inefficient and expensive for resources; (2) the concept of centralized / central Service Desk . It is possible to reduce the Service Desk office by merging dislocated teams into one central location; (3) the concept of a virtual Service Desk. The state of play used to create a uniquely centralized / imagined Service Desk depends largely on the use of technology, the Internet and support tools, and is especially used in situations where staff are stationed. Outsourcing can be supported in multiple combinations; (4) the concept of "follow the Sun" . Provides a solution to requests during standard business hours, and at the end of business hours and hand over responsibilities to the Dislocated Service Desk Office (another time zone). The idea is to provide 24-hour work coverage, with good controls, information transfer processes and relatively small cost; (5) Specialized Service Desk Groups. In some situations, it is better to create specialized Service Desk groups to deal with specific IT situations. Faster incident management, better knowledge and specialist training are achieved ; (6) External Service Desk (work of outside companies), if the official service desk is under the management of external firms (Outsourcing), watch that the number, type and function of the equipment used is appropriate for the users outside the company. Ensure that equipment and procedures are properly researched and that customer requirements are properly covered and prescribed prior to the outsourcing contract. It is not applied in practice as the primary solution due to conditions influencing the orderly functioning of the external company (data sensitivity, use of applications and technical solutions, education required).

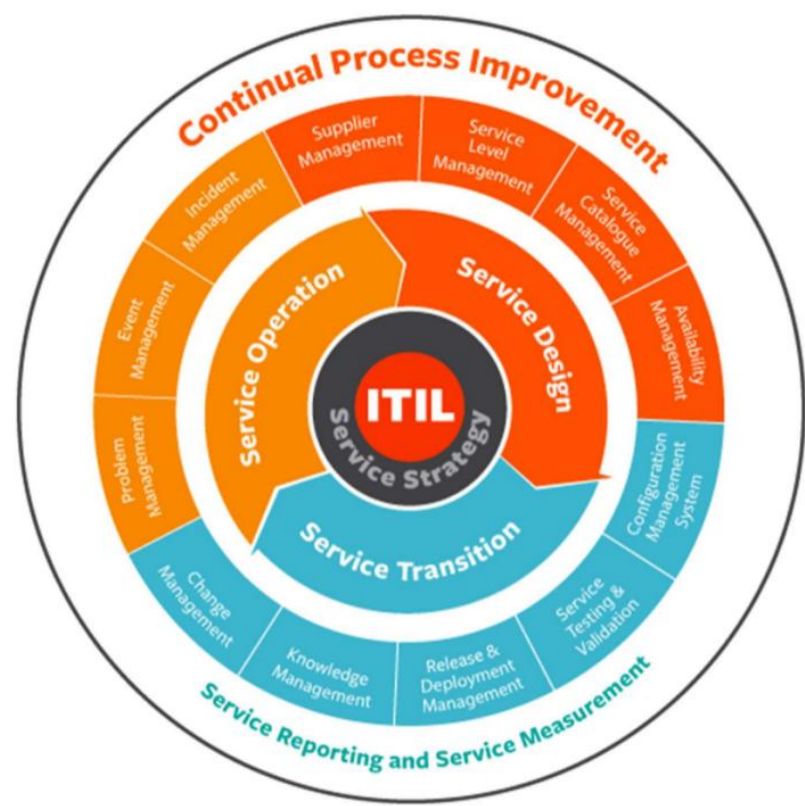

Figure 2. Service life cycle

Source: http://www.bmc.com/guides/itil-introduction.html/, situation on 11.11.2017.

Application of ITIL in implementation (exclusively the proposals of first author Domagoj Car). Today, the values of an effective SDk must be appreciated, because good service often compensates for other deficiencies in an IT firm. In contrast, poorly conceived SDk performance defects can create a bad impression of an otherwise efficient IT firm. That is why it is also important within the SDk : to use a certain type of staff, to direct the work of the manager to make the SDk an attractive place to work, to improve staff retention for a longer period. The exact offer, type, size and location of the SDk depends on the type of business, number of users, geography, complexity of calls, scope of services and other factors. IT firms must decide on the importance of the IT firm, in accordance with customer requirements and overall ITSM strategy. In order to optimize the process in access and resolution, it was necessary to propose a basis for improvement from multiple perspectives, including constant process improvement, selection of more complete tools, removal of obstacles for the detected processes. They may be internal and external in nature. After correcting and refining the process, feedback should be used and further automation work should be done to distribute requests according to predefined rules, in order to create timely actions to interrupt production interruptions. Automation can be directed by considering the following methods: (a) Service Request; (b) Incident; (c) Major incident; (d) Request Problem.

According to the automation introduced, timely alerts will be provided for the application of request status, in order for the provider to be notified of the problem situation, especially production interruptions, and to be a link to the terms of 
the SLA contract, which are assigned to the user for a certain level of service (depending on the contract). Of course, according to a predetermined state of analysis or its requirement, this is arbitrary and depends on current SLA provisions, as well as on the services provided by a particular company in order to avoid a service breakdown (Service Deterioration SDe), which may impair the recurrence of incidents level of service, but first and foremost in the context of moral and representative representation, according to the market. The primary objective of these process improvements and the introduction of automation is to implement a process that would ultimately ensure a smooth flow (with reduced operational use of the tool and focus on problem solving) and would lead to a correction of a previous breach of the SLA contract for outsourced services.

Request cycle in an IT company / ITIL deployment. With regards to ITSM, co-author Domagoj Car independently developed the operational cycle of the request. SDk requires a special toolkit that allows for proper sequencing and transparent processing with the following: a) receiving requests from users. Request, an application that allows you to make a request, which will be successfully transferred to the classification process in the form of event recognition, incident or problem; b) a unified overview of the services and resources of an IT company (Change Management CMDB) . Provides control of company IT services and resources for the problem of reported problem reporting from control and within-company correlations; c) properly set process diagram and direct link to Ticketing application: d) SLA / SLM tools. Application within / outside the existing Ticketing system, that enables classification and assessment of the consequent situation regarding the agreed deadlines under SLA contracts; e) a tool for classifying and conducting incident / problem management; An application that allows the processing of a classified request in the context of an incident with a specified resolution, in terms of escalation documentation and the time required to resolve it. In order to ensure the proper course of events / requests, as well as further classification and resolution of the event, the basic requirement would be to use a single tool. There are several tools available on the market to manage the event cycle, such as the primary tool within the observed SBM IT company (Web App Service Business Manager, author of Micro Focus), while wider alternatives are secured during most, if not all phases. event/event (example BMC application, Freshservice, Smarttrack ) that allows easier request transition, according to a predefined flow. In order for the application solution to be satisfactory, the basic modularity of the tool, as well as the free changing of the process and its adaptation for additional satisfaction in terms of automation and event classification, are for these needs.

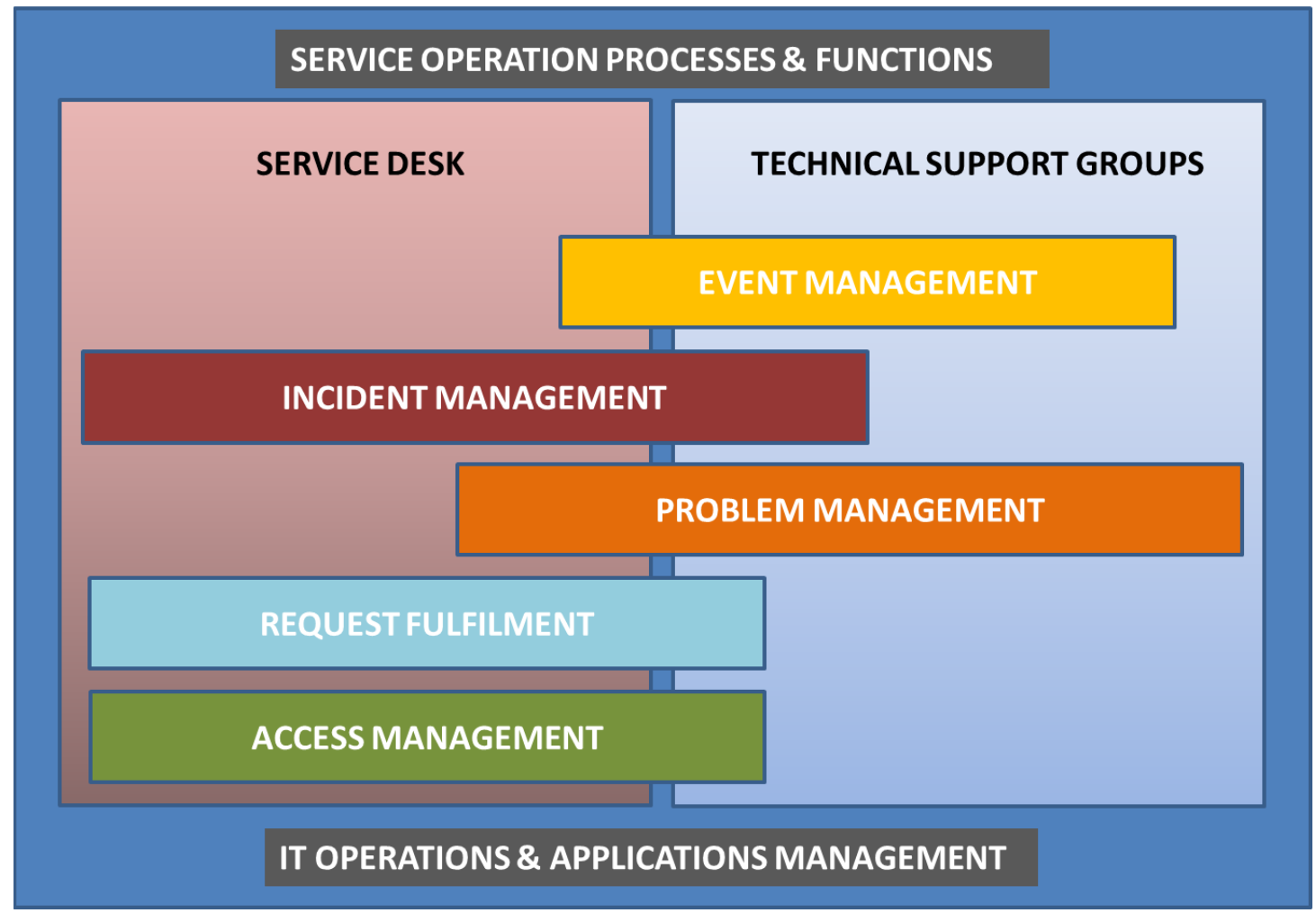

Figure 3. Impact of the SOD phase on the ITIL business of the selected company

Source: https: //pinkelephant.co.uk/guides/it-service-management-2/service- operations /, situation on 11/11/2017. 
For detection and further processing, in accordance with the internal process, an example of modularity is the Freshservice software tool that enables incident, Knowledge Management KM, Service Catalogue SD, CMDB.

Self-service portal for users, which allows isolation of basic ones in the form of replacement of user passwords, which, consequently, reduce the load on the Service Desk department and allow focusing to other requests. The core work of the Service Desk department, and partly the IT environment, is somewhat easy to measure and enhance. For this, the defined strictly measurable KPI values (Key Performance Index) are used, the purpose of which is to present the results obtained in the context of predefined benchmarks. Aforementioned is usable in the incident and in the SLM.

Conclusion: Treatment of the defended Graduation Thesis touched upon the topics covered by the general comparison mode of modern IT management in correlation with the basics of management theory. In IT companies, the basis for harmonized monitoring of trends and developments within the industry requires adaptation to a new set of rules, so that companies can successfully operate larger systems that exert increased pressure on smaller companies of the same type of activity. The problems encountered by young companies in the market are barriers that are difficult to overcome, because they are a consequence of the mode applied from the previous way of understanding business and management. Specific barriers that are more difficult to overcome relate to the focus on knowing the details of process content, rather than adherence which requires precise application, thereby directly affecting the slowdowns of implementation steps involved. In a Service Desk situation at a full management step, the consequent slowdown in timeconsuming resolution is beyond the narrow area of our own / problem-solving domain. The problem can be solved by naming CMDB services and resources, which would greatly reduce the need for process details. In the present day, IT firms are being marketed to adapt to the existing conditions of competition and advancement of like-minded businesses, with a new set of problems that emerge when they use the notion of management and the social component that affect the processes that, in accordance with written rules, they seek to introduce. Consequently, there may be some inertia within implementation due to inter-departmental interests that management does not take in theory as more serious, but is present in a part of Western Europe, where it may emerge as one of the major obstacles to growth. In addition, practical problems may include "communication noise" due to incomplete or extensive internal procedures that make it impossible to apply the steps directly, and which often do not have a linear sequence of communications and management, according to previously defined SLA contracts. In order for the process to function in accordance with the ITIL basics of the post-rollout phase of SO and SDk, the basics require a properly defined procedure and implementation steps in all five phases if the procedure skips the steps of proper implementation of later production changes in the context of changes. Within the early implementation of $\mathbf{C A B}$ verification for an existing service or a new one, it makes it difficult to react and recover it. In order for reaction and willingness to change services, but also to launch new services in a timely manner, it is necessary to look at northern Europe, Asia and North America and similar companies, which try to "blindly" follow and not take into account the social point of view, which also takes into account the perspective of employee friendliness as an additional factor. They give rise to business responsibilities for a more modern Croatia, to persons who do not necessarily fit the business needs of the required positions for their profile. The conclusion is that, by written rules, implementation should be easier, but the additional problems that arise greatly affect the time and time required to introduce them. Recommendations for the implementation of ITIL in companies is a topic that would include a breakdown of specific companies by each of the five basic cycles and would initially try to approach a more "western" way of thinking, or with a direct goal. 


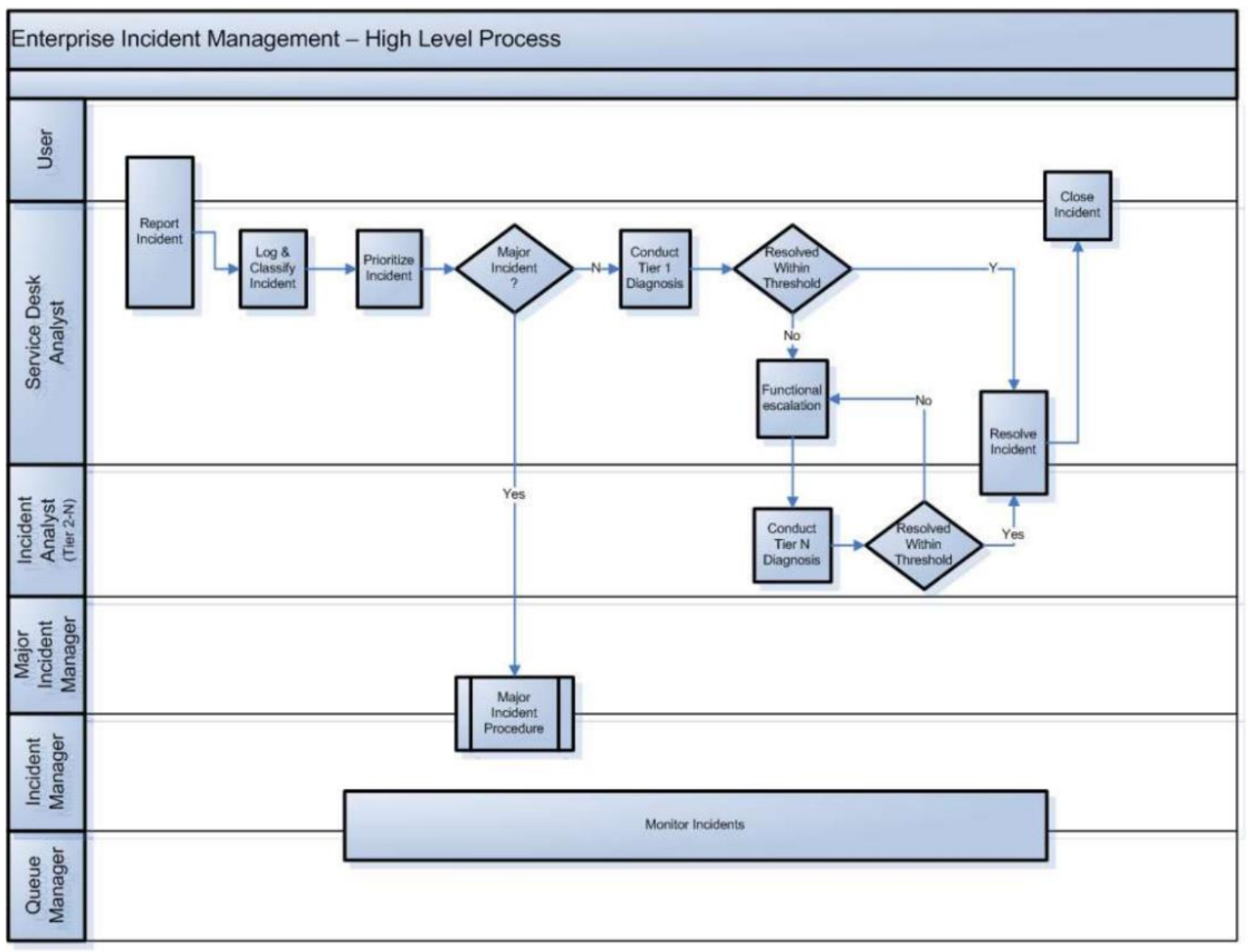

Diagram 1. Cycle service request

Source: https://www.ontario.ca/page/go-its-37-enterprise-incident-management-process, situation on 15.10.2017.

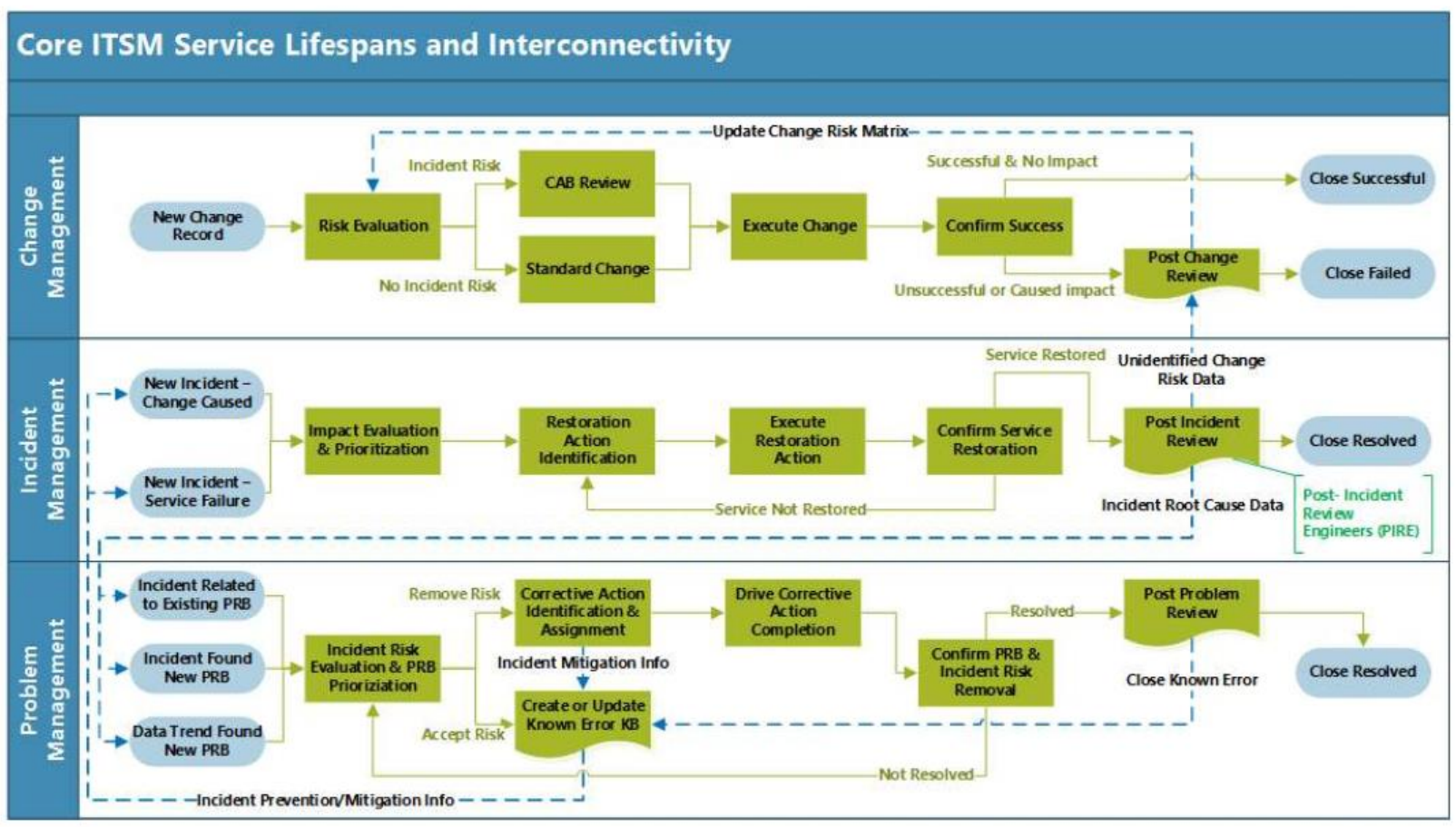

Diagram 2. Core ITSM service lifespans and interconnectivity 
Source: https://www.linkedin.com/pulse/5-problem-management-traps-avoid-missing-itil-role-john-barber, situation on 30.10.2017.

Improvement recommendations. The current concept of request cycle solution is within the scope of the work of Domagoj Car co-author, designed using different tools from different manufacturers to cover all stages of the process, whose non-unification makes it difficult to process requests quickly by phase and quickly, a unified application solution that will enable modularity and unity of management and handling, from the receipt of user requests and the phases mentioned above to completion. A modern IT company has introduced a new service that provides an easier end-user administration solution through an existing core application. Diagram 1. shows the flow of the User Request cycle, which, in coordination with the Service Desk department, undergoes a request or incident detection process. In the case of an incident, the Service Desk department proceeds to further analysis using the IM procedure in the next steps, but in the case of incidents with serious consequences for the business involves one of the following methods, under order. no. 3) the aforementioned Major incident procedure, which includes the additional view of escalation and information as predefined deadlines for eliminating problems. The analysis is focused on using the procedure for IM , or for PM. Practically, the company has recognized the lesser importance of IM that has appeared on 3 different occasions within 30 days, and the same leads to the conclusion that it is a PM. After recovery of the reported service (recorded as an incident), The further sequence will be resolved by the PM path. The problems are analyzed in detail and an attempt is made to find out the root cause of the recurrence. The result usually leads to previous ITIL cycles from the point of view of: 1) Service Transition ST phase: a problem caused by incorrect Service Operations SO in terms of documentation for the end user, according to the stated point of view ; 2) Service Design SD: The problem is caused by problems with the logic of defining or performing the service, and a more exhaustive process that, in rare situations, the end product can return to its original stage to eliminate it. The Service Desk representative, depending on the procedures within the company, notifies representatives of the ITIL cycles mentioned in order for the error to be rectified or analyzed. Practically, the correlation with the basics of management is primarily seen by the Service Desk SD procedures when completing the first stage of request detection. Below, in identifying an incident / problem, it is the responsibility of the analyst to align the multiple teams involved in the solvers, which, with Service Desk inputs at regular intervals and chronological order, will be able to generate output as end executors. Modern IT companies cannot exist without Service Desk SD, who with a broad knowledge of the business of the company and the serenity of the processes involved, must contribute coordination and management skills to the infrequent number of firms involved, whose realization depends largely on the employee in charge and the ability to coordinate and manage, which can be defined by the short or long course and a successful completion of a reported problem. In addition to the above steps of the Service Desk, the responsible ones also include information from the provider and the types involved in the predefined terms, depending on the type of request and official notes to the partners in accordance with the service switch agreements. To minimize the possibility of errors during production modification of the existing applications / products or the introduction of new, introduces the appearance of the body for advice (Change Advisory Board CAB ), the Service Desk SD whose assignment is to analyze in detail the previous inputs from Service Desk SD and users, the impact and potential threats to an existing partner under SLA agreements. Diagram 2. shows the type of request previously identified as Incident, or is preparing to introduce production changes for an existing product/problem. Modern companies, when defining ITIL business basics, are not aware that successful implementation requires a quality know-how and mental approach, which despite defined steps for procedures, requires a different approach to the problem, which includes logical analysis and rational management of resources, after implementation. The above is necessary, so that in the cycle of ITIL, the desires, needs, or most importantly and consequently scenarios in terms of removing them in a problematic situation in production could be predicted.

\section{ACKNOWLEDGMENTS}

This article is about processing Experimental final work, which Domagoj Car defended with thesis called "Application of ITIL Method for Management in Practice" on Graduate Studies.

\section{REFERENCES}

[1] Becker, H., Longoch, I., 1999, Productivity and Menschlichkeit, Stuttgart: VA 
[2] Boddy, D. and Paton, R.A.: Management: An Introduction, Prentice-Hall, London, 1998.

[3] Buble, M.: Basic of Management, 2006, Zagreb: Sinergy

[4] Devenport, C., 1989, Americas Most Admired Corporations, FORTUNE, January 30

[5] Donelly. J.H., Gibson, J.L., Ivancevich., J.M., 1990, Fundamentals of Management, Boston: IRWIN

[6] Drucker, P.: Practicing Leading, Economy, Zagreb, 1961.

[7] Galbraith, J.K., Kazanjin, R., Strategy of Implementation: Structure, Systems an Process, St. Paul: West Publishing, USA

[8] Grochla, F., 1978, Einfuhrung in die Organizationstheorie, Stuttgart: Poeschel,

[9] Hauc, A., 2006, Project Management and Project Business, Zagreb-Zapresic: MEP consult and High School for business and management

[10] Jurina, M.: ORGANIZATION AND MANAGEMENT, High School for Business and Management with right to public "Balthazar Adam Krcelic", Zapresic 2011.

[11] Koontz, H., Weichrich, H., 1990, Essentials of Management, McGraw Hill, New York

[12] Kreitner, R., 2006, Foundation for Management, Boston :: Houghton Mifflin Co

[13] Maslow, A.H. Motivation of Person, Nolit, Belgrade, 1982.

[14] Mintzberg, H., 1979, Structure in 5., Management Science, New York

[15] Peters, T., Waterman, R., 1982, In Search of Excelence, New York: McKinsey

[16] Sikavica, P., Novak, M., 1994, Business organization, Informator, Zagreb

[17] Sikavica, P., Bahtijarević-Šiber, F., 2004. Management, Management Theory and Great Empirical investigation in Croatia, Zagreb: Masmedia

[18] Srića, V., 1992, Principles of Modern Management, Business School, Zagreb

[19] Vila, A., 1994, Organization and organized, Modern organization, Kranj

[20] Vrsec, M., 1993, Organized and leading police, Ministry of Home Affairs MHA, Republic Slovenia, Ljubljana

[21] Weichrich, H., Koontz, H., 1998. Management, Mate, Zagreb

[22] Žugaj, M., Brčić, R., 2003, Management, Varaždin, Faculty of Organization and Informatics, University of Zagreb 